\title{
Perfil Bibliométrico dos Grupos de Pesquisa em Educação do Campo: (2000-2016)
}

\author{
Maria Cristina Piumbato Innocentini Hayashi ${ }^{1}$, Taísa Grasiela Gomes Liduenha Gonçalves ${ }^{2}$ \\ ${ }^{1}$ Universidade Federal de São Carlos - UFSCar, Rodovia Washington Luis, Km 235, São Carlos - SP. Brasil. \\ dmch@ufscar.br. ${ }^{2}$ Universidade Norte do Paraná - UNOPAR.
}

RESUMO. As lutas dos movimentos sociais por uma educação que atenda às demandas e necessidades da população do campo faz parte da agenda de pesquisas dos estudos acadêmicos sobre a Educação do Campo. Visando investigar a configuração da produção de conhecimento sobre essa temática realizou-se um estudo exploratório-descritivo com abordagem cientométrica. Os dados foram coletados na base corrente do Diretório de Grupo de Pesquisas no Brasil do Conselho Nacional de Desenvolvimento Científico e Tecnológico (DGPB/CNPq) e nos currículos Lattes dos líderes dos grupos. Os resultados indicaram a existência de 36 grupos formados entre 2000 e 2016, sendo a maioria da área de Educação $(86,71 \%)$, liderados por 51 pesquisadores com o título de doutores e oito com o título de mestres, com predomínio das mulheres. Os grupos estão localizados na região Nordeste $(33,3 \%)$, Sudeste $(22,2 \%)$, Sul e Norte, com 16,7\% cada e Centro-Oeste, com 11,1\%. Juntos, desenvolvem 106 linhas de pesquisa, com predominância da temática "Processos de Formação de Professores e Educadores do Campo". A produção científica dos líderes dos grupos nos últimos cinco anos totalizou 74 artigos em 52 periódicos, além de 37 livros e 92 capítulos de livros, demonstrando a importância das pesquisas desenvolvidas pelos grupos em Educação do Campo.

Palavras-chave: Educação do Campo, Produção Científica, Bibliometria. 


\title{
Bibliometric Profile of Research Groups in Rural Education: (2000-2016)
}

\begin{abstract}
The struggles of social movements for an education that meets the demands and needs of the rural population is part of the academic studies research agenda on Rural Education. In order to investigate how to set up the production of knowledge on this subject was conducted an exploratory and descriptive study with bibliometric approach. Data were collected in the current base of the Research Group Directory at Brazil's National Scientific and Technological Development Council (DGPB / CNPq) and in the Lattes curricula of group leaders. The results indicated that were formed 36 groups between 2000 and 2016, with most of the area of education $(86.71 \%)$, led by 51 researchers with the title of doctors and eight with the title of master, with a predominance of women. The groups are located in the regions: Northeast (33.3\%), Southeast (22.2\%), South (16.7\%), the North $(16.7 \%)$ and Midwest (11.1\%). Together, they develop 106 lines of research, especially the theme "Teacher Training and Field Educators". The scientific production of the leaders in the past five years totaled 74 articles in 52 journals, as well as 37 books and 92 book chapters, demonstrating the importance of research developed by Rural Education in groups.
\end{abstract}

Keywords: Rural Education, Scientific Production, Bibliometrics. 


\section{Perfil Bibliométrico de los Grupos de Investigación sobre Educación Rural: (2000-2016).}

RESUMEN. Las luchas de los movimientos sociales por una educación que responda a las demandas y los temas de las necesidades de la población rural es parte de la agenda de los estudios de investigación académica sobre Educación Rural. Con el fin de investigar cómo se configura la producción de conocimiento sobre este tema se llevó a cabo un estudio exploratorio descriptivo con enfoque bibliométrico. Los datos fueron recogidos en la base actual del Directorio de Grupos de Investigación del Consejo Nacional de la Ciencia y el Desarrollo Tecnológico (DGPB/CNPq) y en los currículos de los investigadores. Los resultados indicaron la existencia de 36 grupos formados entre 2000 y 2016, con la mayor parte del área de la educación $(86,71 \%)$, dirigidos por 51 doctores y ocho maestros, con un predominio de las mujeres. Los grupos se localizan en el Nordeste $(33,3 \%)$, Sudeste $(22,2 \%)$, el Sur y en el Norte, con un $16,7 \%$ cada uno y en el Medio Oeste, con 11,1\%. Juntos, desarrollan 106 líneas de investigación, en especial en el tema relacionado con "Los maestros y los procesos de formación de profesores de campo". La producción científica de los líderes en los últimos cinco años asciende a 74 artículos publicados en 52 revistas científicas, así como 37 libros y 92 capítulos de libros, lo que demuestra la importancia de la investigación desarrollada por la Educación Rural en grupos.

Palabras-clave: Educación Rural, Producción Científica, Bibliometría. 


\section{Introdução}

O ano de 2010 inaugura o marco legal da Educação do Campo enquanto política pública (Brasil, 2010). Destinada aos agricultores familiares, extrativistas, pescadores artesanais, ribeirinhos, assentados e acampados da reforma agrária, trabalhadores assalariados rurais, quilombolas, caiçaras, povos da floresta, caboclos e outros que produzem suas condições materiais de existência a partir do trabalho no meio rural, essa política de Educação do Campo comprometeu-se a ampliar e qualificar a oferta de educação básica e superior às populações do campo. Entretanto, o direito educacional que deveria ser universal, vem se constituindo de forma focal, separando por grupos, conforme aponta Cury (2005).

Contudo, a luta pela educação de qualidade no campo, conforme argumenta Molina (2003, p. 65), está atrelada ao "espaço de vida e de produção dos povos trabalhadores do campo" traduzindo o anseio de uma nação pautada na igualdade e justiça a todos os cidadãos brasileiros. Essa luta contra estrutura fundiária e política agrícola está engendrada ao contexto educacional do campo, e a partir dessa concepção é que se deu o nome de Conferência por uma Educação Básica do Campo, no sentido de uma luta contínua na construção de um novo projeto para o campo e para a educação.

Assim, a expressão "Educação do Campo" nasceu a no contexto de preparação da I Conferência Nacional por uma Educação Básica do Campo realizada de 27 a 30 de julho de 1998, em Luziânia, no estado de Goiás. A II Conferência Nacional por uma Educação do Campo foi realizada em 2004, e até os dias atuais a Educação do Campo apresenta uma trajetória de contradições, entrelaçadas entre: campo, educação e políticas públicas, embora seja possível afirmar que houve avanços com relação às políticas, práticas e programas educacionais no campo, apesar do enfretamento constante contra as políticas neoliberais na educação e na agricultura, conforme argumenta Caldart (2012).

Para essa autora, a Educação do Campo pode ser entendida, como um “fenômeno da realidade brasileira atual, protagonizado por trabalhadores do campo e suas organizações, que visa incidir sobre a política de educação desde os interesses sociais das comunidades camponesas". (Caldart, 2012, p. 259).

Caldart (2009a, p. 4) também assinala que "o conceito de Educação do Campo é novo, mas já está em disputa exatamente porque o movimento da realidade que ele busca expressar é 
marcado por contradições sociais muito fortes". Assim, não é de estranhar que tanto no meio acadêmico como entre os militantes dos movimentos sociais do campo haja uma discussão conceitual sobre a "Educação do Campo" e "Educação no Campo".

Na visão de Santos, Paludo e Bastos (2010, p.15), a Educação do Campo

[...] nasceu tomando posição no confronto de projetos de educação contra uma visão instrumentalizadora da educação, colocada a serviço das demandas de um determinado modelo de desenvolvimento do campo (que sempre dominou a chamada "educação rural"), a favor da afirmação da educação como formação humana, omnilateral, que também pode ser chamada de integral, porque abarca todas as dimensões do ser humano. Também a Educação do Campo afirma uma educação emancipatória, vinculada a um projeto histórico, de longo prazo, de superação do modo de produção capitalista. Projeto histórico deve ser compreendido como o esforço para transformar, isto é, construir uma nova forma de organização das relações sociais, econômicas, políticas e culturais para a sociedade, que se contraponha à forma atual de organização e de relações, que é a capitalista.

Por sua vez, na visão de Caldart (2009b, p. 41)

[...] o 'do' da Educação do campo tem a ver com esse protagonismo: não é 'para' e nem mesmo 'com': é dos trabalhadores, educação $d o$ campo, dos camponeses, pedagogia do oprimido... Um 'do' que não é dado, mas que precisa ser construído pelo processo de formação dos sujeitos coletivos, sujeitos que lutam para tomar parte da dinâmica social, para se constituir como sujeitos políticos, capazes de influir na agenda política da sociedade. Mas que representa, nos limites 'impostos pelo quadro em que se insere', a emergência efetiva de novos educadores, interrogadores da educação, da sociedade, construtores (pela luta/pressão) de políticas, pensadores da pedagogia, sujeitos de práticas.

De outro ponto de vista, Bezerra (2010, p. 152) questiona se "a discussão deveria se dar em torno de uma educação no campo ou uma educação do campo", e argumenta:

Se entendermos que o processo educacional deve ocorrer no local em que as pessoas residem, devemos falar de uma educação no campo e aí, não haveria a necessidade de se pensar em uma educação específica para o campo, dado que os conhecimentos produzidos pela humanidade devem ser disponibilizados para toda a sociedade. Se entendermos que deve haver uma educação específica para o campo, teríamos que considerar as diversidades apontadas acima e perguntarmos, de que especificidade estamos falando? Partindo deste pressuposto, teríamos que considerar a possibilidade de uma educação para os assentados por programas de reforma agrária, outra para imigrantes, outra para remanescentes de quilombolas e tantas outras quantas são as diferentes realidades do campo. Nesse caso, trabalharíamos apenas com as diversidades e jamais com o que une todos os trabalhadores, que é o pertencer a uma única classe social, a classe dos desprovidos dos meios de 
produção e por isso, vendedores de força de trabalho, explorados pelo capital. [...] Por não considerar a teoria como parte imprescindível da formação do concreto pensado, supervalorizando a prática tomada em seu aspecto fenomênico, individual e utilitarista, a educação do campo cai num pragmatismo exacerbado aproximando-se das tendências pós-modernas. (Bezerra, 2010, p. 152-153).

A despeito das diferentes perspectivas que envolvem o conceito de Educação do Campo tendemos a concordar com o argumento de Caldart (2009a, p. 2) de que

[...] se o conceito de Educação do Campo, como parte da construção de um paradigma teórico e político, não é fixo, fechado, também não pode ser aleatório, arbitrário: qualquer um inventado por alguém, por um grupo, por alguma instituição, por um governo, por um movimento, uma organização social. Pelo nosso referencial teórico, o conceito de Educação do Campo tem raiz na sua materialidade de origem e no movimento histórico da realidade a que se refere.

Esse breve panorama histórico e conceitual sobre a "Educação do Campo" no Brasil compõe o pano de fundo de uma pesquisa $^{\mathrm{i}}$ que foi norteada pelo interesse em investigar os grupos de pesquisa acadêmicos que atuam nessa área no país. A motivação pela análise da realidade educacional dos povos do campo em um estudo com esse enfoque é relevante quando se considera que esses grupos de pesquisa podem contribuir para alargar $\mathrm{o}$ conhecimento sobre a realidade da Educação do Campo na contemporaneidade. Ao mesmo tempo, as pesquisas realizadas por esses grupos podem ampliar o debate sobre as concepções teóricas e metodológicas aplicadas em processos formais e não formais de educação, além de sistematizar experiências já desenvolvidas sobre $\mathrm{o}$ complexo modo de construir novos conhecimentos e intermediações envolvidos na Educação do Campo.

Além dessa introdução o texto está estruturado em mais duas seções contendo a caracterização da pesquisa e descrição dos procedimentos metodológicos adotados, e a apresentação e discussão dos resultados, encerrando com as reflexões finais.

\section{Procedimentos metodológicos}

Optou-se pelo estudo bibliométrico, pois essa abordagem metodológica possibilita construir indicadores destinados a avaliar o desempenho de grupos de pesquisa, de pesquisadores e a produção científica de áreas de conhecimento específicas, entre outras aplicações. Conforme argumentam Silva, Hayashi e Hayashi (2011, p. 113-114) “a análise bibliométrica é um método flexível para 
avaliar a tipologia, a quantidade e a qualidade das fontes de informação citadas em pesquisas". Os indicadores de produção científica, ao serem analisados de modo crítico e aprofundados, permitem traçar um panorama do estado da arte dos temas de interesse pesquisados.

A fonte de dados da pesquisa foi a Plataforma Lattes, sistema de informação científica e tecnológica integrada pelo Diretório de Grupos de Pesquisa no Brasil (DGP) do Conselho Nacional de Desenvolvimento Científico e Tecnológico (CNPq) e o Currículo Lattes. A escolha desses sistemas justifica-se pela sua abrangência.

O DGP/CNPq é um inventário dos grupos de pesquisa científica e tecnológica em atividade no País, e contém informações sobre os recursos humanos (pesquisadores, estudantes e técnicos), linhas de pesquisa, especialidades do conhecimento, produção científica, tecnológica e artística dos grupos de pesquisa, o que permite traçar um perfil da atividade científica, tecnológica e artística existente no país. O currículo Lattes é um padrão nacional de registro das atividades acadêmico-científicas de pesquisadores, e na atualidade é adotado pela maioria das instituições de fomento, universidades e institutos de pesquisa do país. (CNPq, 2016a).
Os dados dos grupos de pesquisa foram coletados na base corrente do DGP, por meio de consulta parametrizada com busca exata dos termos "Educação do Campo" e "Educação no Campo" aplicados ao nome do grupo, e tendo como critérios de inclusão os grupos certificados sem delimitação temporal, com o intuito de contemplar desde o grupo mais antigo até o mais recente. $\mathrm{O}$ alvo do critério de exclusão foram os grupos de pesquisa não atualizados.

$\mathrm{Na}$ base de currículos Plataforma Lattes a produção científica registrada nos últimos cinco anos pelos líderes dos 36 grupos de pesquisa ativos foi coletada tendo como critérios de inclusão publicações dos seguintes tipos: artigos científicos, livros e capítulos de livros cujos títulos apresentaram aderência à temática da "Educação do Campo". Foram excluídos os demais tipos de publicações (trabalhos completos e resumos apresentados em eventos) e aquelas não adequadas ao escopo da pesquisa. A coleta de dados ocorreu em 20 de junho de 2016.

Para registro das informações coletadas foram utilizadas duas planilhas elaboradas com o software Excel ${ }^{\circledR}$, contendo as seguintes variáveis em relação ao perfil dos grupos de pesquisa e da produção científica: 
a) grupos de pesquisa: ano de formação, nome do grupo, instituição e área de conhecimento predominante, nome do grupo, linhas de pesquisa aderentes à temática pesquisada,

b) líderes e pesquisadores: gênero, titulação máxima obtida e obtenção de bolsa de agência de fomento.

b) produção científica: tipo de documento (artigos, livros e capítulos), distribuição anual, perfil dos periódicos.

É válido ressaltar que o conteúdo disponibilizado pelo Diretório dos Grupos de Pesquisa do CNPq é de acesso público, o que exime este estudo de submissão ao Comitê de Ética em Pesquisa com Seres Humanos. A despeito disso, foram seguidos os preceitos éticos necessários para o desenvolvimento da pesquisa, entre eles a honestidade e precisão com relação aos dados coletados para evitar possíveis distorções de dados estatísticos que pudessem comprometer as interpretações.

As etapas de desenvolvimento da pesquisa (Figura 1) foram as seguintes: definição das fontes de dados e do termo de busca nos sistemas de informação; coleta e sistematização dos dados, análise bibliométrica, interpretação e discussão dos resultados. O corpus final da pesquisa foi composto por 36 grupos de pesquisa e 205 publicações registradas pelos líderes de pesquisa em seus currículos disponíveis na Plataforma Lattes.

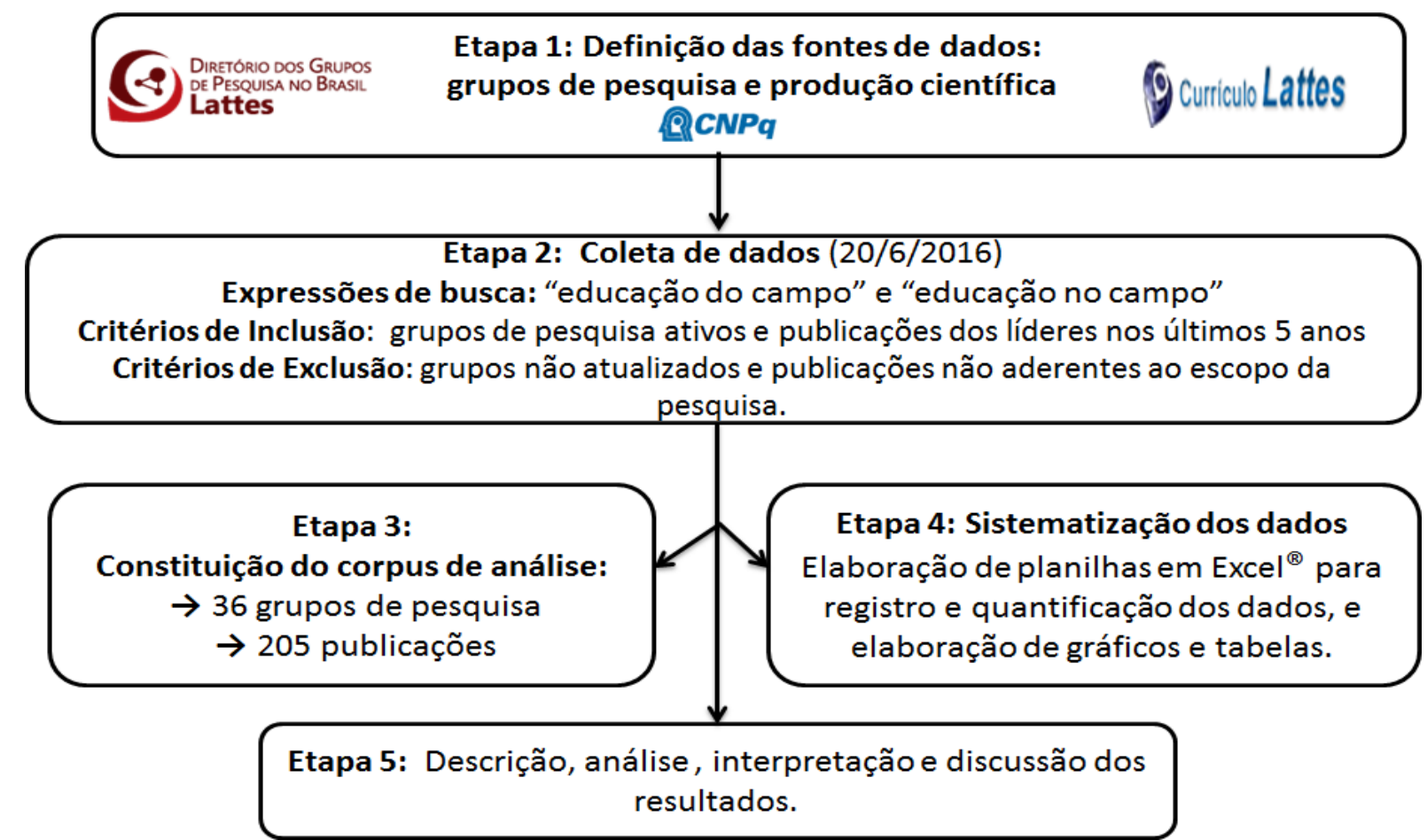

Fonte: Elaboração das autoras

Figura 1 - Fluxograma das etapas da pesquisa 


\section{Perfil dos grupos de pesquisa}

Nesta seção apresentamos o perfil dos grupos de pesquisa em relação às seguintes variáveis: ano de formação, região geográfica, vinculação institucional, nome dos grupos e áreas de conhecimento predominante.

A Figura 2 apresenta a evolução temporal dos 36 grupos de pesquisa identificados como ativos e certificados no DGPB/CNPq. Recorde-se, entretanto, que de acordo com os critérios de exclusão dez grupos de pesquisa não integraram $o$ corpus de análise devido ao status de não atualizado há mais de doze meses $(n=1)$ e até dois anos $(n=9)$ na base corrente do $\mathrm{DGPB} / \mathrm{CNPq}$.

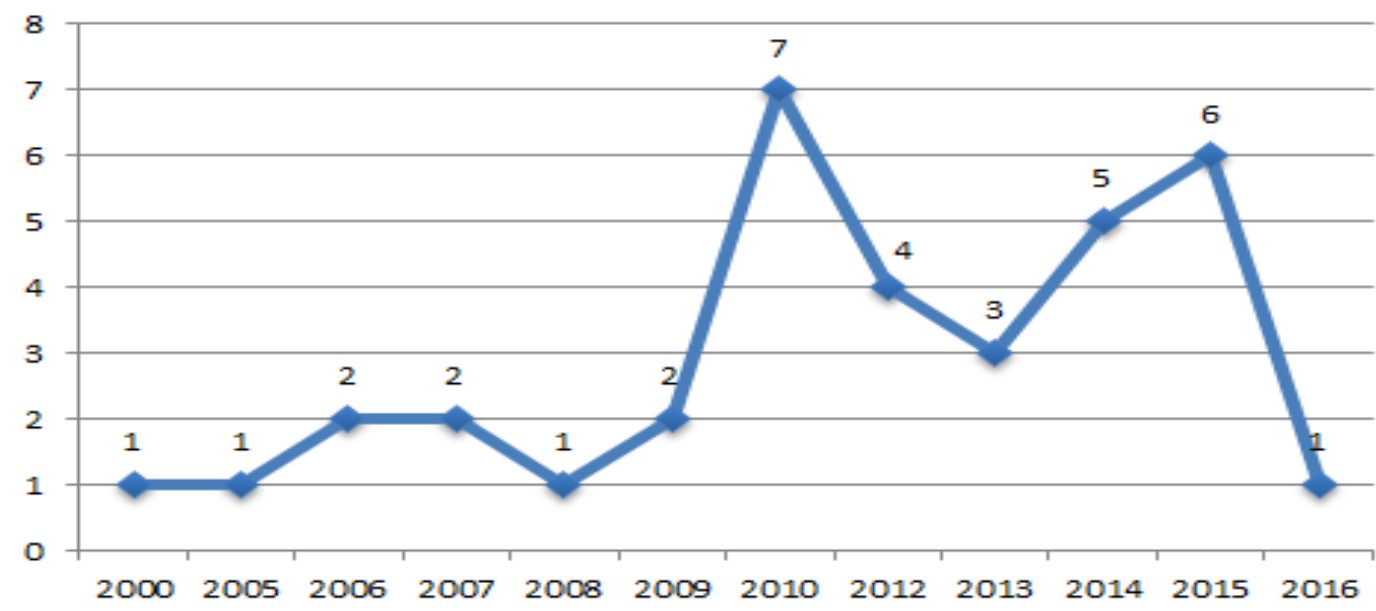

Fonte: Elaboração das autoras

Figura 2 - Evolução temporal dos grupos de pesquisa

Os dados da Figura 2 mostram que o grupo mais antigo foi formado no ano de 2000, com uma lacuna na formação de grupos até 2005 atingindo $25 \%(\mathrm{n}=9)$ do total de grupos em 2009. Em 2010 há um expressivo crescimento $(\mathrm{n}=8) \quad-$ coincidindo com marco legal da política pública de Educação do Campo, com a promulgação do decreto 7.352 - e atingindo $75 \%$. $(\mathrm{n}=27)$ do total de grupos até 2016.
Ao comparar, em valores percentuais, a distribuição do tempo de existência dos grupos de pesquisa analisados $(n=36)$ na base corrente com dos grupos de pesquisa do DGPB/CNPq $(n=35.424)$ por ano de formação na base corrente com a súmula estatística ${ }^{\mathrm{ii}}$ em 2014, observa-se que os grupos com 2 até 9 anos de existência predominam em ambas as bases. Entretanto, o percentual de grupos com menos de dois anos na base 
corrente $(\mathrm{n}=19,4 \%)$ é superior ao da súmula estatística $(\mathrm{n}=0,3 \%), \quad \mathrm{e}$ inversamente, o percentual dos grupos na faixa de 15 até 19 anos é inferior na base corrente, conforme mostram os resultados da Figura 3.

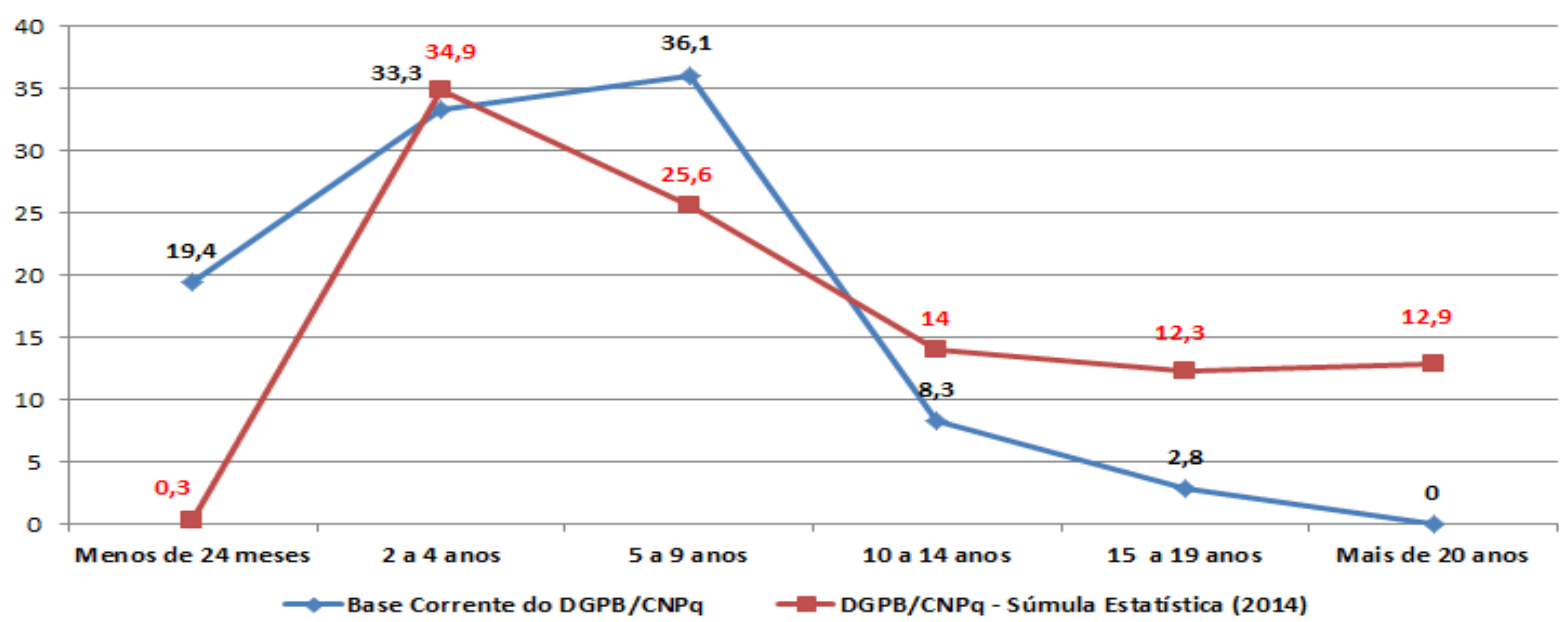

Fonte: Elaboração das autoras

Figura 3 - Distribuição dos grupos de pesquisa por ano de formação

Também foi investigada a vinculação institucional dos grupos de pesquisa e sua distribuição de acordo com as regiões do país, conforme mostram os resultados obtidos na Figura 4.

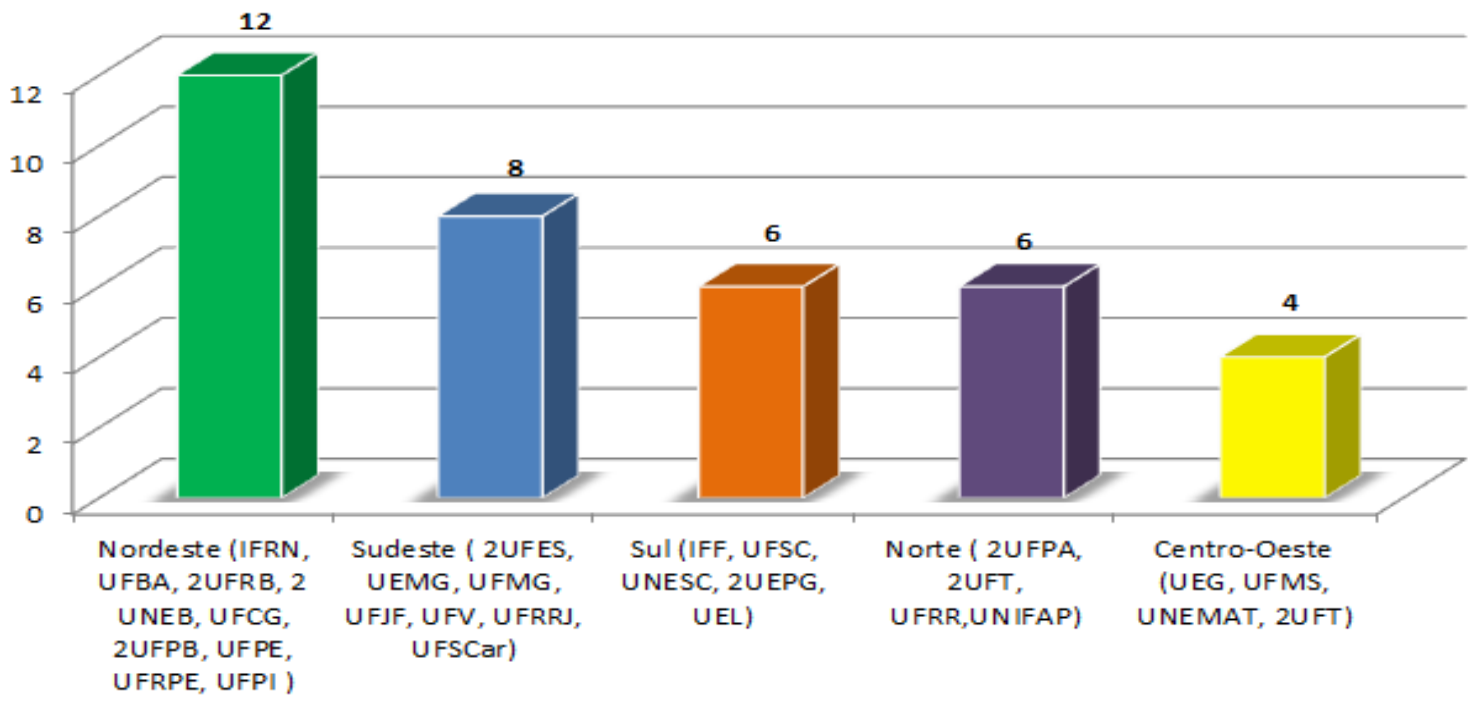

Fonte: Elaboração das autoras

Figura 4 - Distribuição dos grupos por região do país e vinculação institucional 
A pesquisa revelou que $61,1 \%$

$(n=22)$ dos grupos de pesquisa estão localizados nas regiões Nordeste $(n=33,3 \%)$, Norte $(n=16,7 \%)$ e CentroOeste $(n=11,1 \%)$, enquanto que as regiões Sudeste $(n=22,2 \%)$ e Sul $(n=16,7 \%)$ do país reúnem 38,9\% (n=14) dos grupos. Em relação à vinculação institucional dos grupos de pesquisa foram identificadas 29 instituições. O Quadro 1 relaciona os nomes e respectivas instituições de vinculação dos grupos de pesquisa.

\begin{tabular}{|c|c|}
\hline Grupos & Instituições \\
\hline Grupo de Estudo e Pesquisa em Educação do Campo & Universidade Federal da Bahia -UFBA \\
\hline $\begin{array}{l}\text { Grupo de Estudos e Pesquisa em Educação do Campo, Trabalho e } \\
\text { Desenvolvimento A grário }\end{array}$ & $\begin{array}{l}\text { Universidade Federal do Recôncavo da Bahia- } \\
\text { UFRB }\end{array}$ \\
\hline $\begin{array}{l}\text { Observatório da Educação do Campo do Recôncavo e do Vale do } \\
\text { Jequiriçá-B ahia }\end{array}$ & $\begin{array}{l}\text { Universidade Federal do Recôncavo da Bahia- } \\
\text { UFRB }\end{array}$ \\
\hline Educação do Campo e Contemporaneidade & Universidade do Estado da Bahia - UNEB \\
\hline $\begin{array}{l}\text { Educação do Campo, Trabalho, Contra-Hegemonia e Participação } \\
\text { Humana }\end{array}$ & Universidade do Estado da Bahia - UNEB \\
\hline $\begin{array}{l}\text { Educação do Campo, Formação de Professores e Práticas } \\
\text { Pedagógicas }\end{array}$ & $\begin{array}{l}\text { Universidade Federal de Campina Grande - } \\
\text { UFCG }\end{array}$ \\
\hline Agroecologia, Resistência e Educação do Campo & Universidade Federal da Paraiba - UFPB \\
\hline Educação do Campo e Agroecologia & Universidade Federal da Paraiba - UFPB \\
\hline $\begin{array}{l}\text { Grupo de Pesquisa em Educação Matemática nos Contextos da } \\
\text { Educação do Campo }\end{array}$ & Universidade Federal de Pemambuco - UFPE \\
\hline $\begin{array}{l}\text { Educação: Manifestações Textuais e Discursivas da Diversidade } \\
\text { (Formação de Professores e Educação do Campo) }\end{array}$ & $\begin{array}{l}\text { Universidade Federal Rural de Pemambuco - } \\
\text { UFRPE }\end{array}$ \\
\hline Núcleo de Estudos, Pesquisas e Extensão em Educação do Campo & Universidade Federal do Piaui - UFPI \\
\hline ção do Campo & $\begin{array}{l}\text { Instituto Federal de Educação, Ciência e } \\
\text { Tecnologia do Rio Grande do Norte - IFRN }\end{array}$ \\
\hline as, Parcerias e Educação do Campo & Universidade Federal do Espirito Santo- UFES \\
\hline $\begin{array}{l}\text { Grupo de Estudo e Pesquisa em Educação do Campo do Espirito } \\
\text { Santo }\end{array}$ & Universidade Federal do Espirito Santo- UFES \\
\hline Educação do Campo, Ambiente e Saúde & $\begin{array}{l}\text { Universidade Estadual de Minas Gerais - } \\
\text { UEMG }\end{array}$ \\
\hline Núc & Universidade Federal de Minas Gerais - UFMG \\
\hline Trabalho, Movimentos Sociais Populares e Educação do C & Universidade Federal de Juiz de Fora - UFJF \\
\hline Educação do Campo, A1ternância e Reforma Agrária & Universidade Federal de Viçosa - UFV \\
\hline Grupo de Estudos e Pesquisas em Educação no Campo & Universidade Federal de São Carlos - UFSCar \\
\hline $\begin{array}{l}\text { Núcleo de Estudos e Pesquisas em Pedagogia da Alternância, } \\
\text { Educação do Campo e Ensino de Agroecologia }\end{array}$ & $\begin{array}{l}\text { Universidade Federal Rural do Rio de Janeiro - } \\
\text { UFRR }\end{array}$ \\
\hline $\begin{array}{l}\text { Laboratónio de Educação do Campo e Estudos da Reforma } \\
\text { Agrária }\end{array}$ & Universidade Federal de Santa Catarina - I \\
\hline Movimentos Sociais, Educação do Campo e Práticas Pedagógicas & Universidade Estadual de Ponta Grossa - UEPG \\
\hline Trabalho, Educação, Escola Pública e Educação do Campo & Universidade Estadual de Ponta Grossa - UEPG \\
\hline Campo, Movimentos Sociais e & $\begin{array}{l}\text { Universidade Estadual do Centro-Oeste - } \\
\text { UNICENTRO }\end{array}$ \\
\hline Educação do Campo e Agroecologia & Instituto Federal de Farroupilha - IFF \\
\hline $\begin{array}{l}\text { Desenvolvimento Socioeconômico, Agricultura Familiar e } \\
\text { Educação do Campo }\end{array}$ & $\begin{array}{l}\text { Universidade do Extremo Sul Catarinense - } \\
\text { UNESC }\end{array}$ \\
\hline Educação do Campo e Ensino de Geografia & Universidade Estadual de Londrina -UEL \\
\hline $\begin{array}{l}\text { Juventude Rural, Educação do Campo e Movimentos Sociais da } \\
\text { Amazônia }\end{array}$ & Universidade Federal do Amapá -UNIFAP \\
\hline $\begin{array}{l}\text { Sociedade, Estado e Educação: Govemos Municipais e Educação } \\
\text { do Campo }\end{array}$ & Universidade Federal do Pará - UFPA \\
\hline $\begin{array}{l}\text { Grupo de Estudo, Pesquisa e Extensão em Educação do Campo na } \\
\text { Região Tocantina }\end{array}$ & Universidade Federal do Pará - UFPA \\
\hline ão do Campo em Roraima & ma - IFRR \\
\hline Agroecologia e Educação do Campo & Universidade Estadual de Goiás - UFG \\
\hline Núcleo de Estudos e Pesquisas da Educação do Campo & $\begin{array}{l}\text { Universidade Federal de Mato Grosso do Sul - } \\
\text { UFMS }\end{array}$ \\
\hline Múltiplos Olhares Pedagógicos da Educaçã & $\begin{array}{l}\text { Universidade do Estado de Mato Grosso - } \\
\text { UNEMAT }\end{array}$ \\
\hline Grupo de Estudos e Pesquisas en & Universidade Federal de Tocantins - UFT \\
\hline Grupo de Estudos e Pesquisas em Educação do Campo & Universidade Federal de Tocantins - UFT \\
\hline
\end{tabular}

Fonte: Elaboração das autoras

Quadro 1 - Relação nominal e vinculação institucional dos grupos de pesquisa 
Pode-se observar que $24,1 \% \quad(n=7)$ das instituições apresentaram dois grupos de pesquisa cada - UEPG, UFES, UFPA, UFPB, UFRB, UFT e UNEB - e as demais $75,9 \% \quad(n=22)$ foram representadas por apenas um grupo cada. Também chamam atenção no Quadro 1 à existência de um único grupo denominado Grupo de Estudos e Pesquisas em Educação no Campo,
(UFSCar) o que remete ao debate conceitual existente no meio acadêmico sobre a "Educação no Campo" ou "Educação do Campo" já mencionado na introdução desse artigo.

Também foram investigadas as áreas de conhecimento predominantes dos 35 grupos de pesquisa (Figura 5).

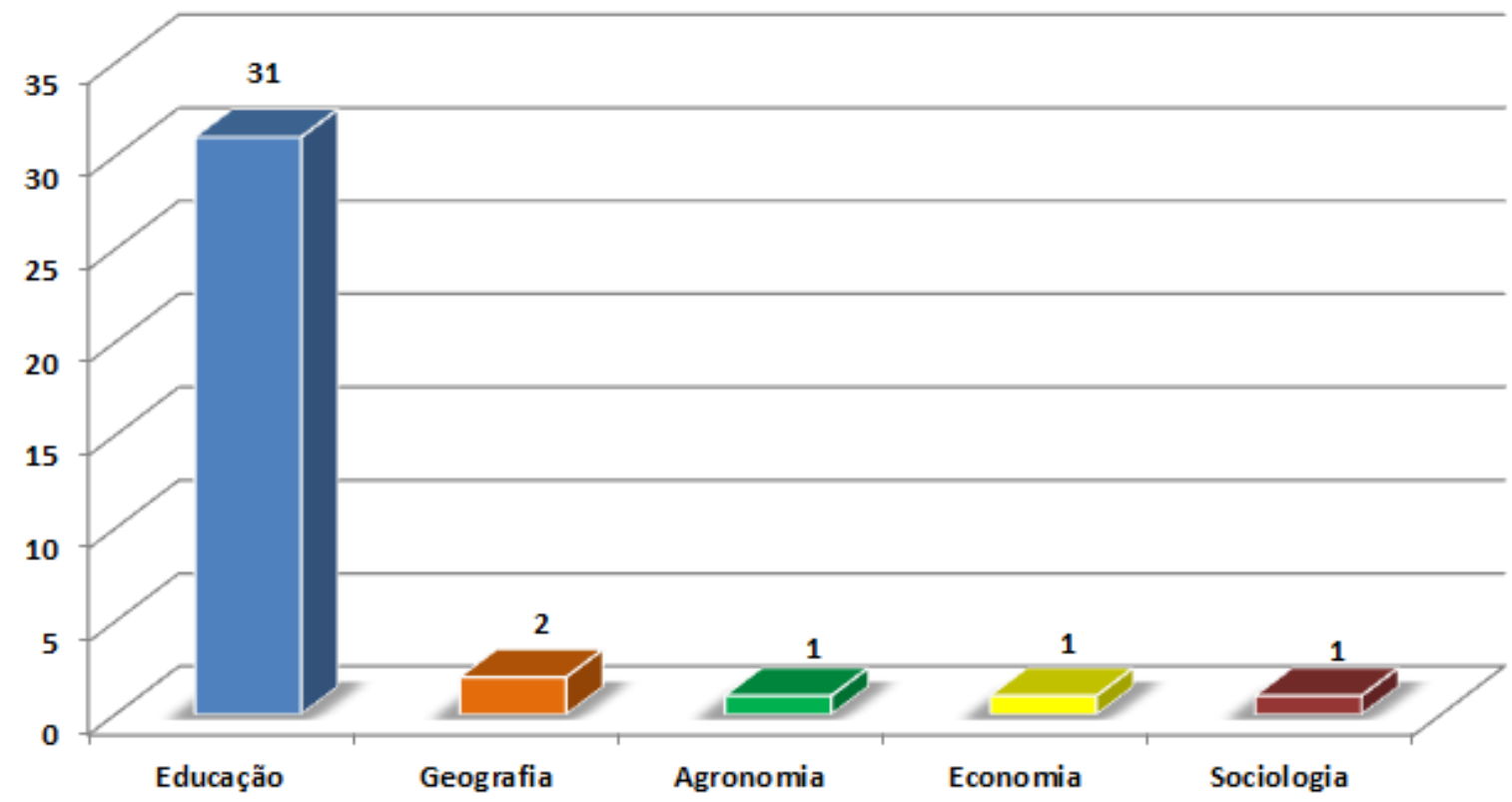

Fonte: Elaboração das autoras

Figura 5 - Distribuição dos grupos de pesquisa por área de conhecimento predominante

Destaca-se na Figura 5 a preponderância da área de Educação com $86,5 \% \quad(n=31)$ do total de grupos de pesquisa, sendo que os demais $13,9 \%$ $(\mathrm{n}=5)$ distribuíram-se entre as áreas de Geografia (n=2) e Agronomia, Economia e Sociologia com um grupo cada representando individualmente $2,8 \%$ do total de áreas. A despeito da área de Educação ser majoritária, a presença de grupos de pesquisa de outras áreas de conhecimento corrobora o entendimento de que o tema da Educação do Campo é interdisciplinar. 


\section{Perfil dos líderes e pesquisadores}

Em relação líderes $(\mathrm{n}=59)$ dos grupos de pesquisa os resultados da pesquisa apontaram que a maioria dos grupos $(n=23)$ possuem dois líderes, enquanto que a minoria $(n=13)$ é liderada por apenas um pesquisador. Além dos líderes, também há um conjunto de pesquisadores $(n=364)$ que integram os grupos de pesquisa.

No que se refere ao perfil dos líderes foram investigadas três variáveis: o gênero, a titulação máxima e a obtenção de bolsas concedidas por agências de fomento.
Em relação ao gênero (Figura 6), os resultados indicaram que não existe discrepância significativa entre os líderes, embora a maioria dos grupos $(54,2 \%)$ seja liderada pelas mulheres $(n=32)$ e os grupos com liderança masculina $(\mathrm{n}=27)$ representem 45,8\% do total. Quando são considerados os pesquisadores que integram os 36 grupos $(n=364)$, a maioria feminina aumenta, atingindo 59,3\% com o total de mulheres $(n=216)$ se sobrepondo aos $40,7 \%$ representado pelos homens $(n=148)$.

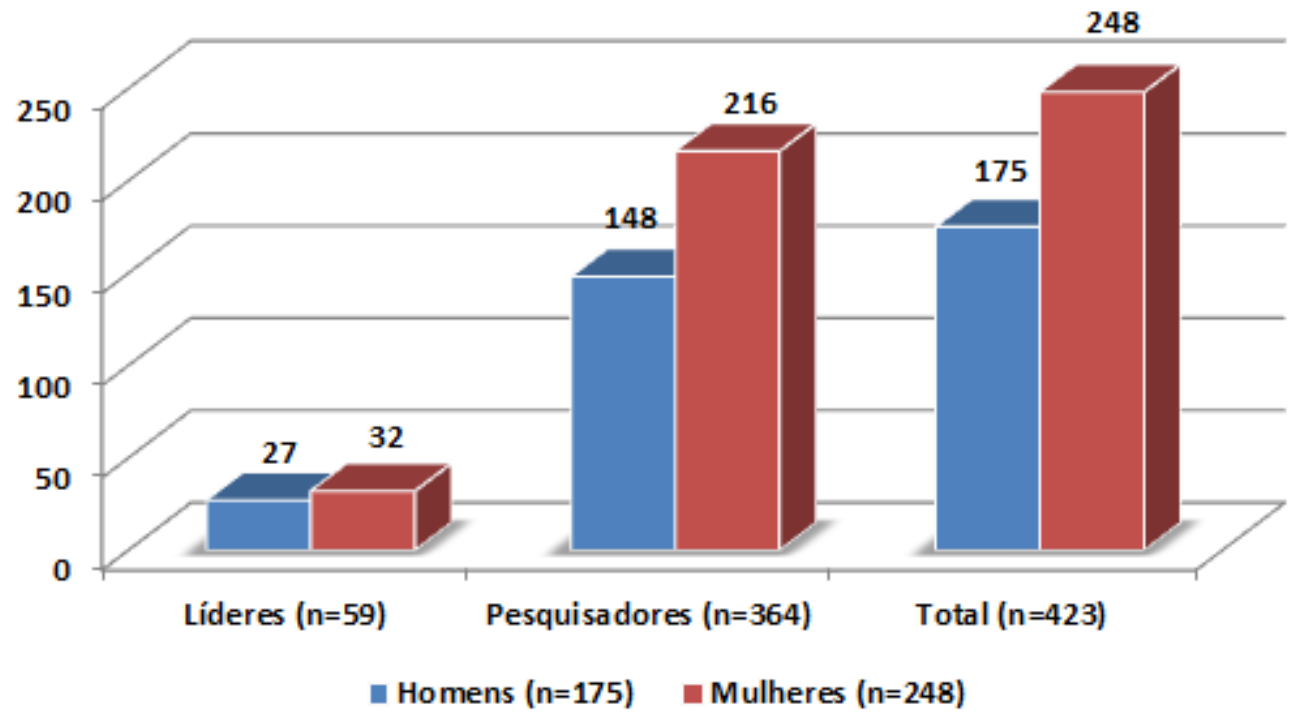

Fonte: Elaboração das autoras

Figura 6 - Distribuição dos líderes e pesquisadores por gênero

Comparativamente à distribuição por gênero na súmula estatística do DGPB/CNPq de 2014, que demonstra equidade entre homens e mulheres, cada um com $50 \%$, a presença feminina entre líderes e pesquisadores dos 36 grupos sobre Educação do Campo é superior.

Também foi investigada a titulação máxima dos líderes, e os resultados obtidos indicaram que $11,7 \%(\mathrm{n}=7)$ possui apenas o título de mestre - liderando grupos dos 
estados do Pará $(n=2)$, Tocantins $(n=2)$, Bahia $(n=1)$, Rio Grande do Norte $(n=1)$ e Goiás $(n=1)$ - enquanto que os demais $88,1 \% \quad(\mathrm{n}=52) \quad$ são doutores. Esses resultados também estão em concordância com os índices da súmula estatística do DGPB/CNPq de 2014, que indica 9,6\% dos líderes possui titulação máxima de mestrado e $89,1 \%$ já concluíram o doutorado. Por sua vez, considerando a distribuição percentual da titulação máxima dos pesquisadores com mestrado segundo a região geográfica do país dos grupos de pesquisa liderados por mestres $(n=7)$ os resultados obtidos apresentaram discrepância em relação aos da súmula estatística de 2014 do CNPq, haja vista que a região Nordeste representou 59,7\% contra $16,6 \%$; a região Norte compareceu com $66.6 \%$ em oposição aos $49,1 \%$ do DGPB/CNPq e a região Centro-Oeste totalizou $25 \%$ frente aos $66,3 \%$ obtidos na base censitária.

A pesquisa também averiguou a obtenção de bolsas concedidas pelos 59 líderes dos 36 grupos de pesquisa, e os resultados apontaram que apenas 13,5\% $(\mathrm{n}=8)$ possuem bolsas em duas modalidades ${ }^{\text {iii. }}$ : produtividade em pesquisa $(n=2)$ - níveis $1 \mathrm{C}$ e 2 , no comitê de Educação - e de extensão B no país (n=6).

A Figura 7 sintetiza os resultados sobre o perfil dos líderes de acordo com a titulação e obtenção de bolsas.

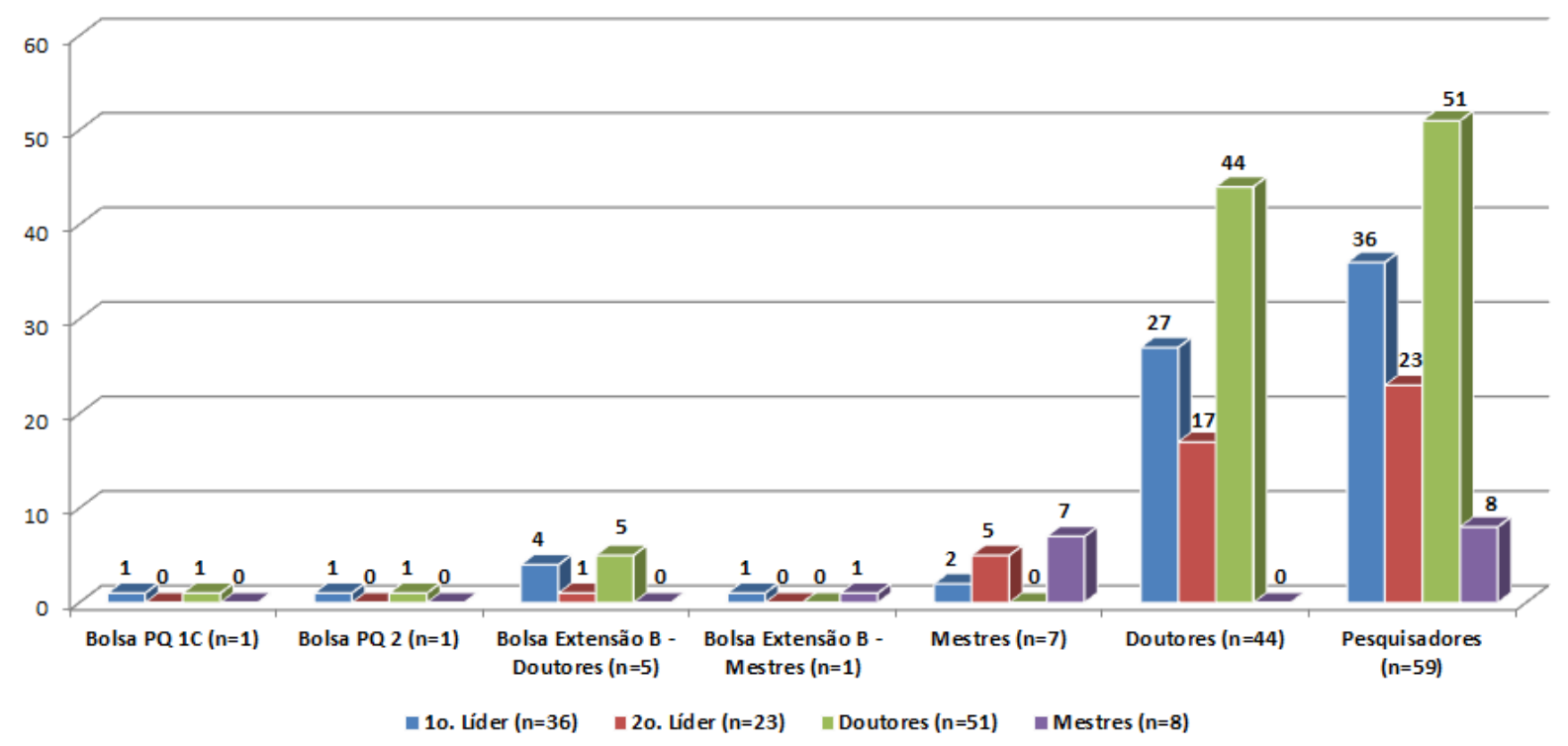

Fonte: Elaboração das autoras

Figura 7 - Perfil dos líderes segundo a titulação e obtenção de bolsas 


\section{As linhas de pesquisa e as temáticas desenvolvidas pelos grupos}

Observou-se que os 36 grupos desenvolvem mais de uma centena de linhas de pesquisa $(n=119)$, sendo que $89,1 \%(\mathrm{n}=106)$ desse total apresenta aderência à temática da "Educação do Campo". A distribuição dessas linhas de pesquisa por grupo revelou que a maioria (n-26) dos grupos desenvolve duas $(n=10)$, três $(n=8)$ até quatro linhas de pesquisa $(\mathrm{n}=8)$, totalizando $71,7 \%(\mathrm{n}=76)$ do total de linhas $(n=106)$. Ainda há dez grupos de pesquisa que desenvolvem os demais $28,3 \% \quad(n=30)$ do total de linhas de pesquisa, sendo respectivamente, seis grupos com uma linha $(n=6)$, dois grupos com cinco linhas $(n=10)$ e dois grupos com sete linhas de pesquisa $(n=14)$ cada. (Figura 8).

Figura 8 - Distribuição das linhas de pesquisa por grupos

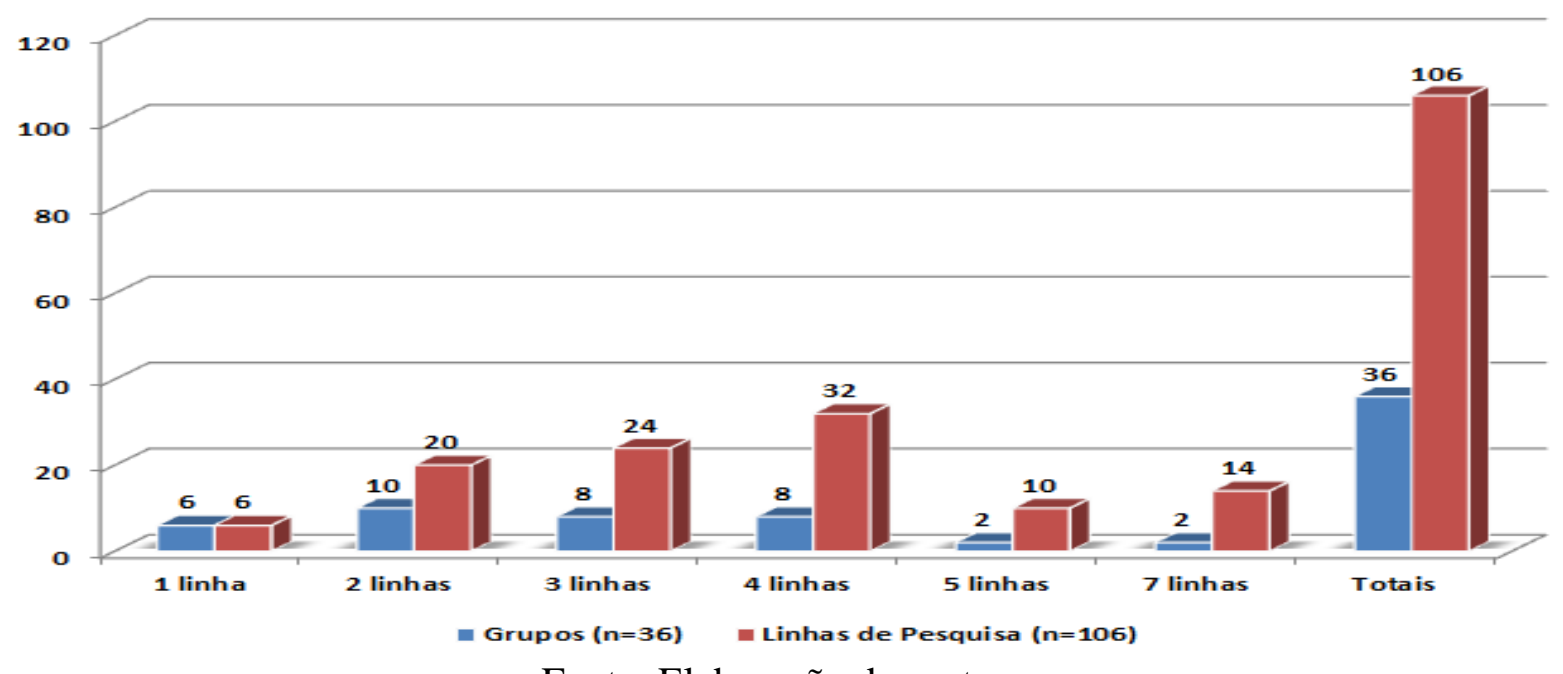

Fonte: Elaboração das autoras

No intuito de melhor sistematizar os resultados obtidos, as linhas de pesquisa foram agrupadas em dez temáticas (Tabela
1), embora seja válido mencionar que cada linha de pesquisa pode desenvolver mais de uma temática.

\begin{tabular}{l|c}
\hline \multicolumn{1}{c|}{ Temáticas } & Linhas \\
\hline Processos de Formação de Professores e Educadores do Campo & 24 \\
\hline $\begin{array}{l}\text { Escolas do Campo: alternância, multisseriação, currículo, práticas } \\
\text { educativas e processos de ensino aprendizagem, alfabetização e } \\
\text { letramento. }\end{array}$ & 18 \\
\hline Movimentos Sociais do Campo & 17 \\
\hline Políticas Públicas de Educação do Campo & 14 \\
\hline Educação de Jovens e Adultos (EJA) e Juventude do Campo. & 10 \\
\hline
\end{tabular}




\begin{tabular}{|c|c|}
\hline $\begin{array}{l}\text { Questões agrárias no campo: reforma agrária, desenvolvimento (agrário, } \\
\text { rural, socioeconômico, sustentável) agroecologia, agricultura familiar, } \\
\text { saúde e segurança ambiental. }\end{array}$ & 7 \\
\hline $\begin{array}{l}\text { Educação do campo em estados das regiões brasileiras: N (Amapá, } \\
\text { Roraima, Tocantins); NE (Piauí, Bahia), CO (Goiás) SE (Espírito Santo), S } \\
\text { (Paraná, Santa Catarina, Rio Grande do Sul). }\end{array}$ & 6 \\
\hline $\begin{array}{l}\text { Diversidade e Identidade na Educação do Campo: Educação Especial, } \\
\text { Educação Indígena, Quilombolas, Populações Ribeirinhas e das Florestas. }\end{array}$ & 5 \\
\hline $\begin{array}{l}\text { Ensino de disciplinas específicas no contexto da Educação do Campo: } \\
\text { Geografia, Matemática, Informática. }\end{array}$ & 3 \\
\hline Memória e História da Educação do Campo. & 2 \\
\hline Total & 106 \\
\hline
\end{tabular}

Fonte: Elaboração das autoras

Tabela 1 - Temáticas desenvolvidas nas linhas de pesquisa

Os resultados expostos na Tabela 1 mostram que cinco temáticas foram mais abordadas pelas linhas de pesquisa $(n=83)$ e totalizaram 78,3\%, a saber: "Processos de Formação de Professores e Educadores do Campo" $(\mathrm{n}=22,6 \%)$, "Escolas do Campo" ( $\mathrm{n}=16,9 \%)$, "Movimentos Sociais do Campo" ( $\mathrm{n}=16 \%)$, "Políticas Públicas de Educação do Campo" $(n=13,2 \%)$ e "EJA e Juventude do Campo" ( $n=9,4 \%)$. As demais temáticas representaram juntas

\section{A produção científica dos líderes dos grupos de pesquisa}

A pesquisa identificou a produção científica representada por artigos, livros e
$21,7 \%(n=23)$ do total, e entre elas merece destaque a pequena representatividade $(n=1)$ da linha de pesquisa "Educação Especial" integrada à temática da "Diversidade e Identidade", sinalizando que este é uma temática que urge ser abordado pelos grupos de pesquisa, haja vista a presença de pessoas com deficiência no campo, conforme relatado por Caiado e Meletti (2011).

capítulos de livros que foi publicada pelos líderes dos grupos de pesquisa $(n=59)$ nos últimos cinco anos, isto é, no período entre 2012 e 2016 totalizando 205 publicações (Figura 9). 


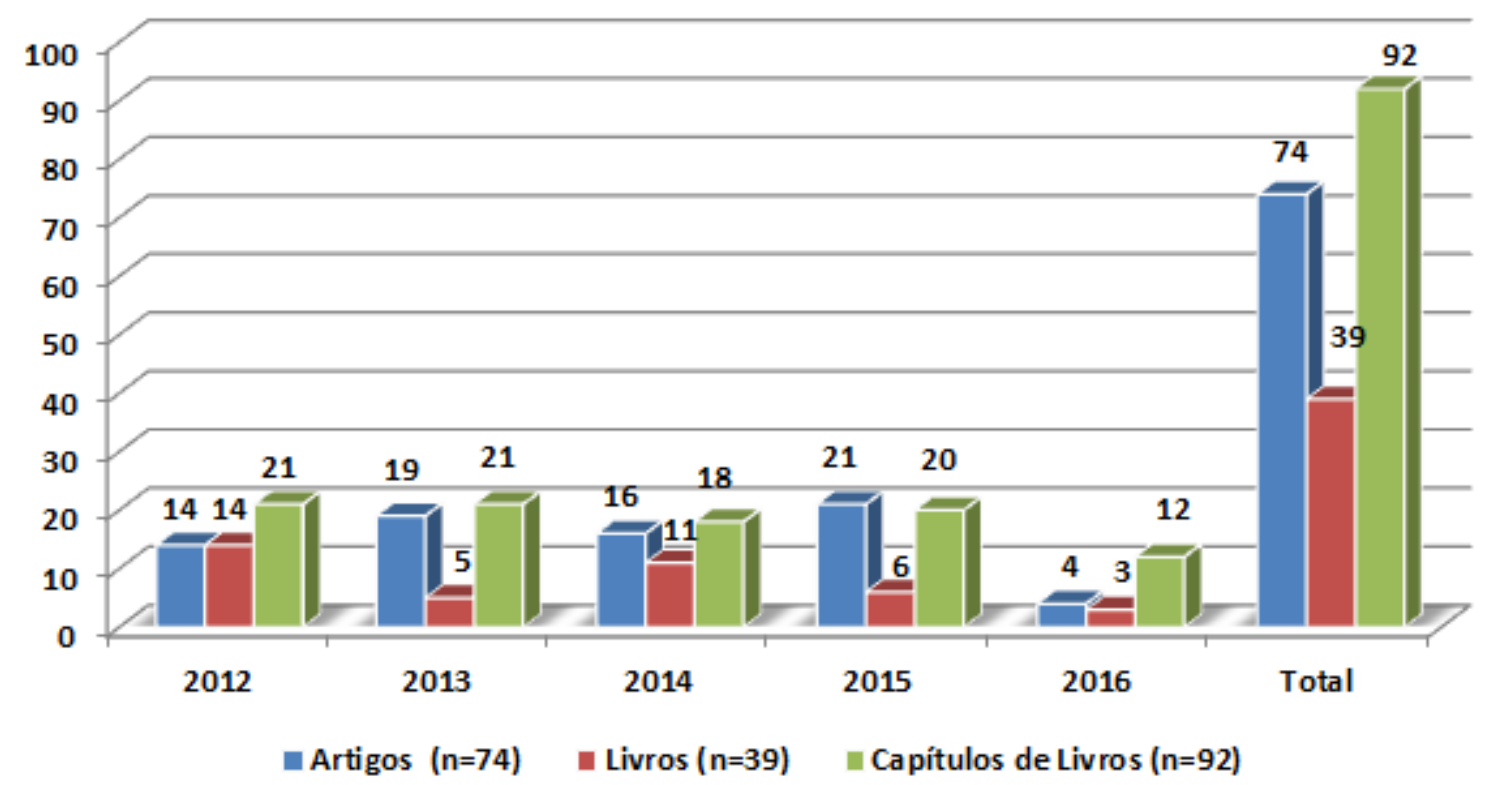

Fonte: Elaboração das autoras

Figura 9 - Produção científica dos líderes dos grupos de pesquisa (2012-2016)

Os resultados da Figura 9 mostram que o tipo de produção científica mais valorizada pelos líderes para divulgar o resultado de suas pesquisas são os capítulos de livros ( $\mathrm{n}=92)$. Juntamente com os livros $(n=3)$ esses tipos de publicações os artigos científicos $(n=74)$. Verificou-se ainda que $32,7 \% \quad(n=19)$ dos líderes dos grupos de pesquisa não possui nenhuma publicação aderente à temática "Educação do Campo" nos últimos cinco anos. Além disso, dois líderes não possuem qualquer tipo de publicação registrada no Currículo Lattes, mesmo em anos anteriores. Ou seja, o total de publicações identificado $(n=205)$ refere-se à produção científica de $67,2 \%$ ( $\mathrm{n}=39)$ dos líderes.

Também foi investigado o perfil dos periódicos $(\mathrm{n}=52)$ selecionados pelos líderes para divulgar suas publicações. 


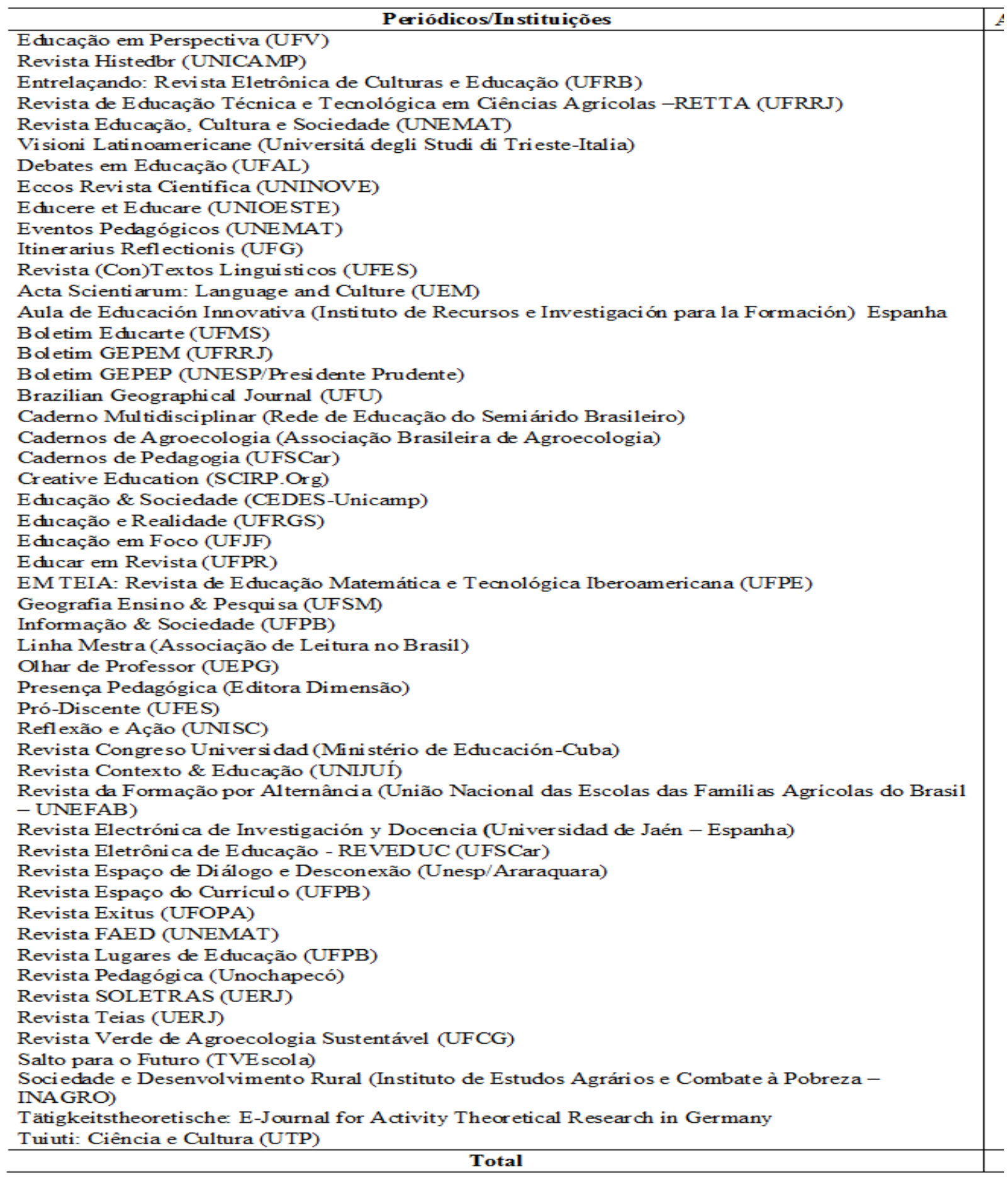

Fonte: Elaboração das autoras

Tabela 2 - Distribuição dos artigos segundo o título dos periódicos

Em relação à distribuição dos periódicos $\quad(\mathrm{n}=52)$ por vinculação institucional observou-se que $26,9 \%$ $(n=14)$ são publicados por seis instituições: UNEMAT $(n=3)$, UFPB $(n=3)$, Unicamp $(\mathrm{n}=2)$, UERJ $(\mathrm{n}=2)$, UFRRJ $(\mathrm{n}=2)$, UFES $(n=2)$ e UERJ $(n=2)$, enquanto que os demais periódicos $(\mathrm{n}=38)$ são vinculados a diferentes instituições do país ( $\mathrm{n}=32$ ), e do 
exterior $(n=6)$ : China $(n=1)$, Cuba $(n=1)$, Espanha (n=2) e Rússia $(n=1)$.

Os resultados também indicaram que poucos periódicos $(\mathrm{n}=10)$ publicaram o maior número de artigos - entre cinco e dois artigos cada - totalizando 45,9\% $(n=34)$ dessa tipologia documental, enquanto que a maioria dos periódicos, representando $54 \%$ do total $(n=40)$ publicou apenas um artigo cada.

Considerando a classificação de periódicos $(\mathrm{n}=52)$ na lista Qualis/Capes
(Figura 10) os resultados apontaram que a maioria $(n=35)$ não está classificada $(n=22)$ ou situa-se nos estratos mais baixos: B3 (n=5), B4 (n=3), B5 (n=3), C $(n=2)$ - inclusive os periódicos de Cuba, Espanha, Itália e Rússia - e a minoria $(n=15)$ pertence aos estratos mais altos: A1 $(n=4)$, B1 $(n=6)$, com um periódico da China, e B2 ( $n=5)$.

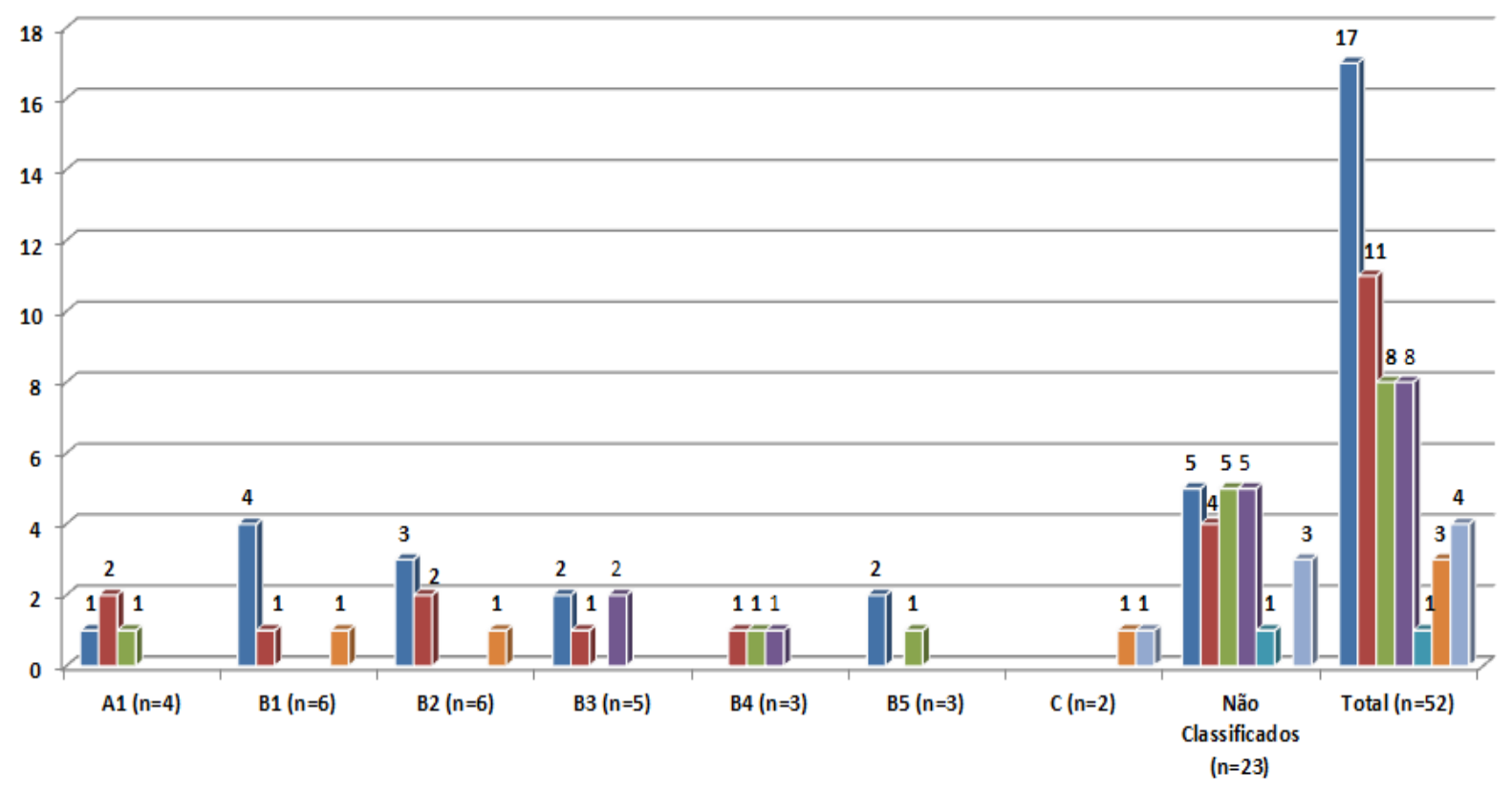

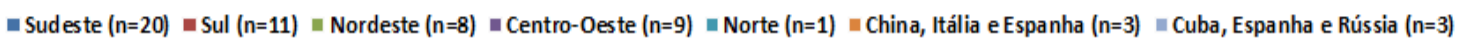

Fonte: Elaboração das autoras

Figura 10 - Distribuição geográfica dos periódicos e classificação na lista Qualis/Capes

Em relação à distribuição geográfica dos periódicos, a Figura 10 mostra que a maioria está concentrada nas regiões Sudeste $(\mathrm{n}=17)$, Sul $(\mathrm{n}=11)$, Nordeste $(n=8)$ e Centro-Oeste $(n=8)$ e em outros países da Também foram identificados periódicos localizados na Ásia $(\mathrm{n}=1)$, Europa $(n=4)$ e América Central $(n=1)$. 


\section{Considerações Finais}

Ao finalizar este artigo, os resultados descritos e analisados permitiram traçar a configuração dos 36 grupos de pesquisa acadêmicos certificados e atualizados no Diretório de Grupos de Pesquisa no Brasil/CNPq que atuam com a temática da "Educação do Campo".

Sintetizando os principais achados, foi possível observar que a maior parte dos grupos foi formada na primeira década do século XXI, passados quase 20 anos desde o início das lutas empreendidas pelos movimentos sociais e do estabelecimento dos marcos institucionais da Educação do Campo.

Em termos da localização geográfica dos grupos de pesquisa observaram-se disparidades na distribuição com preponderância de grupos nas regiões Nordeste, Norte e Centro-Oeste em relação aos grupos do Sul e Sudeste brasileiro, parecendo refletir a própria história das lutas sociais pela terra e pela Educação do Campo no país.

Entre outros aspectos, o perfil dos 59 líderes e 364 pesquisadores dos 36 grupos de pesquisa analisados em relação ao gênero revelou que a participação feminina é majoritária. Tais resultados vão ao encontro de outros estudos sobre gênero na ciência, entre eles os obtidos por Rigolin, Hayashi e Hayashi (2013).

O estudo também revelou que entre as dez temáticas de pesquisa investigadas no interior das 106 linhas de pesquisa desenvolvidas pelos grupos de pesquisa em "Educação do Campo" as de maior incidência se referem aos "Processos de Formação de Professores e Educadores do Campo", "Escolas do Campo", "Movimentos Sociais do Campo" e "Políticas Públicas de Educação do Campo".

Finalmente, o perfil da produção científica dos líderes dos grupos de pesquisa nos últimos cinco anos revelou que prevalece entre os autores a preferência por publicações do tipo livros e capítulos de livros sobre os artigos publicados em periódicos científicos. Por sua vez, a maioria dos periódicos que divulgam as pesquisa realizadas pelos grupos de pesquisa são institucionais, isto é, ligados a instituições de ensino superior e/ou programas de pós-graduação do país. Há poucos trabalhos divulgados em periódicos internacionais e quando isso ocorreu houve preferência pelas publicações ibero-americanas.

Cabe ressaltar, ainda, que os resultados obtidos podem estar limitados por alguns aspectos, por exemplo: a utilização de filtros que restringiram as 
buscas aos nomes dos grupos que excluiu os grupos não atualizados, bem como a limitação aos últimos cinco anos da produção científica registrada nos currículos dos líderes. A despeito disso, o panorama traçado dos grupos de pesquisa em Educação do Campo permitiu compreender que essa temática ainda merece maior espaço na agenda de pesquisas acadêmicas.

\section{Referências}

Bezerra Neto L. N. (2010). Educação do campo ou educação no campo? Revista Histedbr On-Line, 38, 150-168.

Brasil. (2010). Decreto $n^{o}$ 7.352, de 4 de novembro de 2010. Dispõe sobre a política de educação do campo e o Programa Nacional de Educação na Reforma Agrária-PRONERA. 2010. Recuperado em 20 de junho, 2016, de http://www.planalto.gov.br.

Caiado, K. R. M., \& Meletti, S. M. F. (2011). Educação especial na educação do campo: 20 anos de silêncio no GT 15. Revista Brasileira de Educação Especial, 17.

Caldart, R. S. (2012). Educação do campo. In R. S. CALDART, I. B. PEREIRA, P. ALENTEJANO, \& G. FRIGOTTO (Orgs.). Dicionário da Educação do Campo (p. 259-267). Rio de Janeiro: Escola Politécnica de Saúde Joaquim Venâncio.

Caldart, R. S. (2009a). Sobre educação do campo. In UFES. Programa Educação do Campo: Curso Lato Senso sobre Educação do Campo. 2009a. Recuperado em 20 de junho, 2016 , de http://web2.ufes.br/educacaodocampo/dow n/cdrom1/i_edu.html.

Caldart, R. S. (2009b). Educação do campo: notas para uma análise de percurso. Trabalho, Educação e Saúde, 7(1), 35-64, mar./jun. 2009b.

CNPq. (2016a). Plataforma Lattes. Recuperado em 20 de junho, 2016 de: http://lattes.cnpq.br/

CNPq. (2016b) Diretório de Grupos de Pesquisa no Brasil. Súmula estatística. 2016b. Recuperado em: 20 de junho, 2016, de: http://lattes.cnpq.br/web/dgp/sobre14

CNPq. (2016c). Modalidades de bolsas no país. Recuperado em 20 de junho, 2016, de: http://cnpq.br/apresentacao13.

Cury, C. R. J. (2005). Políticas inclusivas e compensatórias na educação básica. Cadernos de Pesquisa, 35, 11-32.

Fernandes, B. M. (1999). Brasil: 500 anos de luta pela terra. Cultura Vozes, 93(2), 112.

Gonçalves, T. G. L., \& Hayashi, M. C. P. I. (2014). Estudo bibliométrico sobre educação do campo para jovens e adultos deficientes. Série Estudos (UCDB), 38, 129-149.

Molina, M. C. (2003). A contribuição do PRONERA na construção de políticas públicas de educação do campo $e$ desenvolvimento sustentável. (Tese de Doutorado). Universidade de Brasília, Brasília.

Ribeiro, M. (2012). Educação Rural. In Caldart, R. S., I. B. Pereira, P. Alentejano, \& Frigotto, G. (Orgs.). Dicionário da Educação do Campo (p. 295-301). Rio de Janeiro: Escola Politécnica de Saúde Joaquim Venâncio.

Rigolin, C. C. D., Hayashi, C. R. M., \& Hayashi, M. C. P. I. (2013). Métricas da 
participação feminina na ciência e na tecnologia no contexto dos INCTs: primeiras aproximações. Liinc em Revista, 9(1), 143-170.

Santos, C. F., Paludo, C., \& Bastos, R. (2010). Concepção de Educação do Campo. In N. Z. Taffarel, C. L. Santos Junior, M. O. Escobar, M. O; A. D’Agostini, E. S. A. Figueiredo, \& M. Titton (Orgs.). Cadernos didáticos sobre educação no campo. Salvador, Universidade Federal da Bahia, 2010.

Silva, M. R. da; Hayashi, C. R. M., \& Hayashi, M. C. P. I. (2011). Análise bibliométrica e cientométrica: desafios aos especialistas que atuam no campo. InCID: Revista de Ciência da Informação $e$ Documentação, 2, 110-129.

\footnotetext{
${ }^{\mathrm{i}}$ Trata-se da pesquisa "Produção de conhecimento sobre Educação do Campo" com resultados já divulgados em Gonçalves e Hayashi (2014), e com outros textos em fase final de elaboração.
}

ii A súmula estatística apresenta um pequeno conjunto de tabelas e gráficos selecionados, com informações que sintetizam o conteúdo da base de dados e fornecem um retrato da capacidade instalada de pesquisa no país. Com descritivo, fornece pistas analíticas sobre determinadas características desse retrato. (CNPq, 2016b).

iii A bolsa de Produtividade em Pesquisa é uma modalidade concedida aos pesquisadores que se destaquem entre seus pares, valorizando sua produção científica segundo critérios normativos. A bolsa de Extensão no País destina-se a apoiar profissionais e especialistas visando ao desenvolvimento de atividades de extensão inovadora ou transferência de tecnologia. Compreende ações voltadas para o desenvolvimento de produtos e processos inovadores e a disseminação de conhecimento, cuja relevância possa contribuir para a inclusão social e o desenvolvimento econômico do País. (CNPq, 2016c).
Recebido em: 11/07/2016 Aprovado em: 25/07/2016

Como citar este artigo / How to cite this article / Como citar este artículo:

APA:

Hayashi, M. C. P. I., \& Gonçalves, T. G. G. L. (2016). Perfil bibliométrico dos Grupos de Pesquisa em Educação do Campo: (2000-2016). Rev. Bras. Educ. Camp., 1(1), 4-25.

ABNT:

HAYASHI, M. C. P. I.; GONÇALVES, T. G. G. L. Perfil bibliométrico dos Grupos de Pesquisa em Educação do Campo: (2000-2016). Rev. Bras. Educ. Camp., Tocantinópolis, v. 1, n. 1, p. 04-25, 2016. 